\title{
A Review of the Unique Drug Development Strategy of Indacaterol Acetate/Glycopyrronium Bromide/ Mometasone Furoate: A First-in-Class, Once-Daily, Single-Inhaler, Fixed-Dose Combination Treatment for Asthma
}

\author{
Dominic Brittain · Peter D'Andrea · Emilie Gruen · Motoi Hosoe · Devendra Jain • \\ Juergen Jauernig $\cdot$ Abhijit Pethe $\cdot$ Emil Scosyrev $\cdot$ Ana-Maria Tanase $\cdot$ Hanns-Christian Tillmann
}

Received: October 29, 2021 / Accepted: December 14, 2021 / Published online: January 24, 2022

(C) The Author(s) 2022

\section{ABSTRACT}

A novel, once-daily (o.d.), fixed-dose combination (FDC) of indacaterol acetate (IND), glycopyrronium bromide (GLY), and mometasone furoate $(\mathrm{MF})$, delivered by the inhaler Breezhaler $^{\circledR}$ device, is the first long-acting beta2adrenergic agonist/long-acting muscarinic antagonist/inhaled corticosteroid (LABA/LAMA/ICS) therapy to be approved for maintenance treatment of asthma in adults inadequately controlled on LABA/ICS. The approval of IND/GLY/MF in the European Union (EU) also included an optional electronic sensor and smartphone (or other suitable device) application, making it the first "digital companion" that can be prescribed with an asthma medication. As a result, the European Medicines Agency included this approval as one of the "outstanding contributions

Supplementary Information The online version contains supplementary material available at https:// doi.org/10.1007/s12325-021-02025-w.

D. Brittain $(\varangle) \cdot$ E. Gruen · M. Hosoe - D. Jain .

J. Jauernig · A.-M. Tanase

Novartis Pharma AG, Basel, Switzerland

e-mail: dominic.brittain@novartis.com

P. D'Andrea · A. Pethe · E. Scosyrev

Novartis Pharmaceuticals Corporation, East

Hanover, NJ, USA

H.-C. Tillmann

Novartis Institutes for Biomedical Research,

Translational Medicine, Basel, Switzerland to public health" (for Pneumology/Allergology) in their 2020 highlights report. Alongside IND/ GLY/MF, an o.d. LABA/ICS FDC, IND/MF, was also developed and approved. This review outlines the unique strategy used in the accelerated development of IND/GLY/MF that combined various approaches: (1) selecting individual components with established efficacy/safety, (2) bridging doses to optimize efficacy/safety of IND/GLY/MF and IND/MF delivered via the Breezhaler ${ }^{\circledR}$ device, (3) developing IND/GLY/ MF and IND/MF in parallel, and (4) submission for regulatory approval before formal completion of the pivotal phase III studies. IND/GLY/MF and IND/MF were combined in a single-development plan (PLATINUM program), which comprised four phase III studies: QUARTZ and PALLADIUM evaluated IND/MF while IRIDIUM and ARGON evaluated IND/GLY/MF. A unique feature was the inclusion of two LABA/ICS comparators in the pivotal IRIDIUM study-IND/MF as an internal comparator, and high-dose salmeterol xinafoate/ fluticasone propionate (SAL/FLU) as a marketed comparator. In the ARGON study, IND/GLY/MF was compared against o.d. tiotropium (via Respimat ${ }^{\circledR}$ ) plus twice-daily (b.i.d.) high-dose SAL/FLU (via Diskus ${ }^{\circledR}$ ). As a result of this development strategy, the development and approval of IND/GLY/MF was accelerated by ca. 4 years as against what would be expected from a traditional approach, novel data were generated, and a unique optional digital companion was approved in the EU. 
Keywords: Accelerated development strategy; Asthma; Digital companion; Indacaterol acetate/glycopyrronium bromide/mometasone furoate; LABA/LAMA/ICS; Once daily; Single inhaler

\section{Key Summary Points}

A fixed-dose combination of indacaterol acetate (IND), glycopyrronium bromide (GLY), and mometasone furoate (MF), delivered by the inhaler Breezhaler ${ }^{\circledR}$ device, is the first once-daily, long-acting beta2-adrenergic agonist/long-acting muscarinic antagonist/inhaled corticosteroid (LABA/LAMA/ICS) therapy to be approved for maintenance treatment of asthma in adults inadequately controlled on LABA/ICS.

The approval of IND/GLY/MF in the European Union also includes an optional electronic sensor and smartphone (or other suitable device) application, making it the first "digital companion" that can be prescribed with an asthma medication.

Alongside IND/GLY/MF, a once-daily LABA/ICS fixed-dose combination, IND/ $\mathrm{MF}$, was also developed.

A unique development strategy was devised for IND/GLY/MF, which accelerated the development of once-daily IND/GLY/MF by ca. 4 years, thereby enabling earlier patient access to this treatment.

\section{DIGITAL FEATURES}

This article is published with digital features, including a talking head video, to facilitate understanding of the article. To view digital features for this article go to https://doi.org/10. 6084/m9.figshare.17198222.

\section{INTRODUCTION}

A novel, once-daily (o.d.) inhaled fixed-dose combination (FDC) of indacaterol acetate (IND), glycopyrronium bromide (GLY), and mometasone furoate $(\mathrm{MF})$, delivered by the inhaler Breezhaler ${ }^{\circledR}$ device, is the first long-acting beta agonist/long-acting muscarinic antagonist/inhaled corticosteroid (LABA/LAMA/ICS) therapy to be approved for maintenance treatment of inadequately controlled asthma $[1,2]$. Currently, this FDC is approved in over 50 countries worldwide including in the European Union (EU) member states (as well as in the UK, Switzerland, Iceland, Norway, and Liechtenstein), Australia, Canada, China, and Japan [3]. The EU approval of the IND/GLY/MF FDC also included an optional electronic sensor and a smartphone (or other suitable device) application (app) that together provide inhalation confirmation, medication reminders, and access to patient objective data (disease-related symptoms and rescue medication use) to support therapeutic decisions, making it the first "digital companion" that can be prescribed with an asthma medication. As a result, the European Medicines Agency (EMA) has listed IND/GLY/ MF Breezhaler ${ }^{\circledR}$ as one of the "outstanding contributions to public health" in its 2020 highlights report (for Pneumology/Allergology) [4]. In this review, we describe the unique strategy used in the accelerated development of IND/GLY/MF, alongside the corresponding LABA/ICS FDC (IND/MF), which was developed in parallel, for the treatment of inadequately controlled asthma. This novel approach to drug development could be of interest to anyone involved in developing new safe and effective medicines, including academic researchers, pharmaceutical companies, and health authorities.

\section{UNMET NEEDS FOR MORE EFFECTIVE, EASY-TO-USE ASTHMA TREATMENTS}

Patients with inadequately controlled asthma are at an increased risk of exacerbations, 
hospitalizations, or death [5-7]. In general, ICSbased therapies are the cornerstone of treatment options in asthma. The Global Initiative for Asthma (GINA) 2021 strategy recommends the addition of a LABA to medium- or high-dose ICS as the preferred controller treatment option for patients at steps 4 and 5 [8]. However, despite treatment with LABA/ICS, some patients may still have persistent uncontrolled asthma. There are limited treatment options in these patients; therefore LAMA may be considered as an addon therapy [8].

Poor treatment adherence is also a risk factor for future exacerbations in patients with asthma, independent of symptom control [8]. Some of the known barriers to adherence to inhaled treatment include complicated dosing regimens, improper use of inhalers, and misunderstanding of the role of controller medications that contribute to poor treatment outcomes. It is critical to note that the use of multiple and often different devices represents a significant burden for patients with asthma [9]. The availability of LABA/LAMA/ICS or LABA/ ICS in a single inhaler to be used as an o.d. regimen may thus offer advantages in terms of improved adherence. This, in turn, may help in achieving better asthma control; indeed, better adherence and improved patient compliance to medication has been observed with o.d. dosing [10-12].

Another potential treatment option for patients with severe asthma is the use of biologics, especially in patients who are symptomatic despite treatment with LABA/ICS. However, the high cost of biologic therapy along with access challenges limits their widespread clinical use $[8,13]$. Thus, there is a clear unmet need for the development of new affordable and effective medicines that provide better treatment options to patients with inadequately controlled asthma [14].

\section{APPROACH TO AN ACCELERATED AND UNIQUE DRUG DEVELOPMENT STRATEGY}

IND/GLY/MF, the first-in-class LABA/LAMA/ICS for asthma, equipped with the first digital companion (optional electronic sensor and a smartphone [or other suitable device] app) that can be prescribed alongside a treatment for uncontrolled asthma in the EU, and IND/MF, a LABA/ICS FDC, are o.d., single-inhaler FDCs envisioned to provide effective treatment options for patients with asthma that offer increased potential for treatment adherence and improved outcomes [2, 3].

A unique development strategy for IND/ GLY/MF was devised to accelerate the drug development process and, thereby, its availability for patients. Novel approaches of this development strategy included (1) selecting individual components with established efficacy and safety profiles, (2) bridging doses to optimize efficacy and safety of IND/GLY/MF and IND/MF delivered via the Breezhaler ${ }^{\circledR}$ device, (3) developing IND/GLY/MF and IND/ MF in parallel, in contrast to the traditional sequential approach for developing combination medicines (i.e., first LABA/ICS, followed by LABA/LAMA/ICS), and (4) submission for approval before the pivotal phase III studies had formally completed. These aspects are discussed in detail in the sections below.

This article is based on previously conducted studies and does not contain any new studies with human participants or animals performed by any of the authors.

\section{Selecting Individual Components with Established Efficacy and Safety Profiles}

Indacaterol (IND), an ultra-LABA with a fast onset of action and sustained bronchodilator effect delivered by the Breezhaler ${ }^{\circledR}$ device, is approved at o.d. doses of $150 \mu \mathrm{g}$ and $300 \mu \mathrm{g}$ for the treatment of chronic obstructive pulmonary disease (COPD) [15, 16]. Glycopyrronium (GLY), a LAMA that provides 24 -h bronchodilation with fast onset of action delivered via the Breezhaler ${ }^{\circledR}$ device, is approved at an o.d. dose of $50 \mu \mathrm{g}$ for the treatment of COPD [17]. An FDC of IND and GLY, delivered via the Breezhaler ${ }^{\circledR}$ device, is approved for the treatment of COPD [18]. Although IND and GLY were already approved for the treatment of COPD, 
these molecules also demonstrated efficacy in patients with asthma $[19,20]$. Mometasone furoate (MF), a potent corticosteroid delivered via the Twisthaler ${ }^{\circledR}$ device, is approved at doses of $200 \mu \mathrm{g}$ o.d., $400 \mu \mathrm{g}$ o.d., and $400 \mu \mathrm{g}$ twice daily (b.i.d.) for the treatment of asthma [21-23]. On the basis of this evidence, IND, GLY, and MF were considered as potential molecules for IND/GLY/MF FDC. Moreover, the selection of these three individual components provided flexibility in making use of the available toxicology, pharmacology, and preclinical data, thereby paving a way directly to clinical studies.

\section{Dose-Finding Strategy and Dose-Bridging Approach}

IND (acetate salt) $150 \mu \mathrm{g}$ o.d. was considered an optimal dose to advance to phase III studies for IND/GLY/MF and IND/MF [24]. No alterations in fine particle mass of IND in either of the combinations meant that no dose adjustments were necessary [25]. The dose of GLY selected for IND/GLY/MF is the approved dose for COPD—50 $\mu \mathrm{g}$ o.d. delivered via the Breezhaler ${ }^{\circledR}$ device [26].

During the development process, the device used for delivery of drugs is as critical as the active pharmaceutical ingredients. IND and GLY have been approved for inhalation via the Breezhaler $^{\circledR}$ device, whereas MF is approved for inhalation via the Twisthaler $^{\circledR}$ device $[15,17,23]$. Therefore, a stepwise bridging approach was implemented to facilitate the bridging of MF doses from Twisthaler ${ }^{\circledR}$ to Breezhaler $^{\circledR}$ and in IND/GLY/MF and IND/MF formulations [27, 28]. MF at doses of 80, 160, and $320 \mu \mathrm{g}$ delivered via the Breezhaler ${ }^{\circledR}$ device was assessed to be comparable to MF 200, 400, and $800 \mu \mathrm{g}$ (two inhalations of $400 \mu \mathrm{g}$ ) delivered via the Twisthaler ${ }^{\circledR}$ device (Table 1 ), and these adjusted doses were confirmed via a pharmacokinetic/pharmacodynamic study program at different MF dose levels [27-30]. The confirmed doses of MF were then used for the IND/MF FDC. As a result of a pharmaceutical interaction within the IND/GLY/MF formulation, there was an increase in the MF fine particle mass in this FDC compared to the same nominal MF dose in IND/MF. Hence, MF $80 \mu$ g o.d. (medium-dose strength) and $160 \mu \mathrm{g}$ o.d. (high-dose strength) in the IND/GLY/MF formulation provided comparable ICS efficacy/dose strength to MF $160 \mu \mathrm{g}$ o.d. (medium-dose strength) and $320 \mu$ g o.d. (high-dose strength) in the IND/MF formulation, respectively; the low-dose strength of MF in IND/ GLY/MF was not developed. The comparable fine particle mass is expected to result in comparable delivery of MF to the lung and comparable systemic MF exposure between the corresponding doses of IND/GLY/MF and IND/MF [28].

\section{Benefits of Using the Breezhaler ${ }^{\circledR}$ Device}

Breezhaler $^{\circledR}$ is a capsule-based unit-dose dry powder inhaler (DPI) with low airflow resistance, which makes it easier for patients with

Table 1 Doses of MF as monotherapy and as fixed-dose combination used in the clinical development program for IND/ GLY/MF and IND/MF

\begin{tabular}{llll}
\hline & Monotherapy & IND/MF & IND/GLY/MF \\
\hline MF & & \\
Dose level (strength) & Via Twisthaler $^{\circledR}[30]$ & Via Breezhaler $^{\circledR}[38]$ & Via Breezhaler $^{\circledR}[36]$ \\
Low & $200 \mu \mathrm{g}$ & $80 \mu \mathrm{g}$ & Not developed \\
Medium & $400 \mu \mathrm{g}$ & $160 \mu \mathrm{g}$ & $80 \mu \mathrm{g}$ \\
High & $800 \mu \mathrm{g}$ & $320 \mu \mathrm{g}$ & $160 \mu \mathrm{g}$ \\
\hline
\end{tabular}

MF $800 \mu \mathrm{g}$ is administered as two inhalations of MF $400 \mu \mathrm{g}$

$G L Y$ glycopyrronium bromide, $I N D$ indacaterol acetate, $M F$ mometasone furoate 
bronchial asthma of varying airway obstruction to achieve the inhalation flow rate required for lung deposition of the medication [31]. Evidence suggests that DPIs have a lower carbon footprint than metered dose inhalers (MDIs) that use potent greenhouse gases as propellents [32]. As Breezhaler ${ }^{\circledR}$ is a DPI free from hydrofluoroalkane/chlorofluorocarbon propellants (HFA/CFC), it is considered to have a reduced carbon footprint and thereby a low impact on the environment [3]. A "cradle-tograve" carbon footprint study conducted on two Breezhaler ${ }^{\circledR}$ inhaled combinations (IND/GLY/ MF and IND/MF FDCs) reported a low carbon footprint with the assessed Breezhaler ${ }^{\circledR}$, in line with the literature on DPIs [33, 34].

\section{Inclusion of an Optional Electronic Sensor and Application for the IND/GLY/MF Breezhaler $^{\circledR}$}

The IND/GLY/MF Breezhaler ${ }^{\circledR}$ included an optional electronic sensor linked to a paired smartphone (or other suitable device) app (Propeller Health). Both the sensor and app send patients reminders to take their prescribed doses. The app records and stores data (Fig. 1) that the patient can share with their clinician to help inform their treatment plan [3]. Inhalation of the medication through the Breezhaler ${ }^{\circledR}$
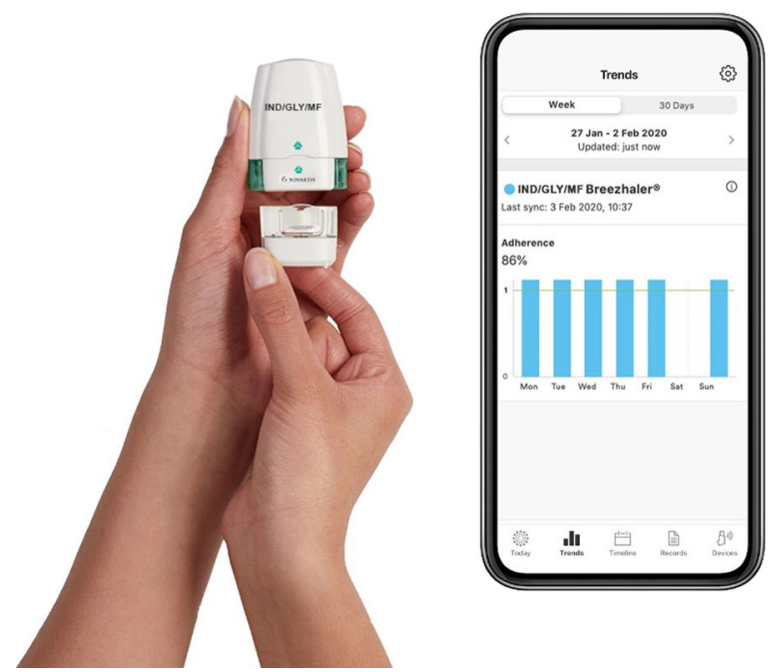

Fig. 1 The Breezhaler ${ }^{\circledR}$ device with the Propeller Health ${ }^{\circledR}$ sensor and smartphone app. Image (C) Propeller Health device triggers the sensor to recognize, record, and wirelessly transmit time and date of medication usage to the patient's mobile app and to the healthcare provider's web app. This passive system helps patients monitor the use of their Breezhaler ${ }^{\circledR}$ inhaler. Additionally, the patient can input their disease-related symptoms and rescue medication use in the app. This information supports patient understanding of their asthma and helps build engagement with their treatment plan and clinician [3]. IND/GLY/MF was submitted and received for regulatory approval as a package with the electronic sensor and app in the EU [3].

\section{Acceleration Steps in Phase III Program}

IND/GLY/MF and IND/MF were combined in a single-development plan (PLATINUM program), rather than the traditional sequential approach of evaluation of efficacy and safety of LABA/ICS first followed by LABA/LAMA/ICS. The PLATINUM program included four clinical trials, namely QUARTZ, PALLADIUM, IRIDIUM, and ARGON. The first two studies evaluated IND/MF whereas the last two evaluated IND/ GLY/MF [35-38]. In the IRIDIUM study, medium- and high-doses of IND/MF, as well as highdose salmeterol xinafoate/fluticasone propionate (SAL/FLU), were evaluated as comparators to IND/GLY/MF (Table 2). We estimate that this combined parallel approach (PALLADIUM and IRIDIUM studies in parallel) helped in accelerating the development and approval of IND/ GLY/MF by ca. 4 years compared to the traditional sequential approach for developing combination medicines. Moreover, Novartis sought agreement from regulatory authorities for parallel development and that a single pivotal study for each of the FDCs could be acceptable, provided that the results are statistically compelling and clinically relevant. Hence, one robust clinical study was designed for IND/GLY/MF and one for IND/MF, with both studies being conducted in parallel. Clinical study data related to IND/GLY/MF and IND/ MF were submitted for regulatory approval while both pivotal PALLADIUM and IRIDIUM 
Table 2 Overview of the PLATINUM phase 3 clinical development program

\begin{tabular}{|c|c|c|c|}
\hline Study (NCT number) & $\begin{array}{l}\text { Study duration } \\
\text { (weeks) }\end{array}$ & Study treatment arms & $N$ \\
\hline \multirow{2}{*}{$\begin{array}{l}\text { QUARTZ } \\
\text { (NCT02892344) }\end{array}$} & \multirow[t]{2}{*}{12} & IND/MF low-dose $\left(150 / 80 \mu\right.$ g o.d.) via Breezhaler ${ }^{\circledR}$ & 398 \\
\hline & & MF low-dose $\left(200 \mu\right.$ g o.d.) via Twisthaler ${ }^{\circledR}$ & 404 \\
\hline \multirow{5}{*}{$\begin{array}{l}\text { PALLADIUM } \\
\qquad(\text { NCT02554786) }\end{array}$} & \multirow[t]{5}{*}{52} & IND/MF medium-dose $(150 / 160 \mu$ g o.d. $)$ via Breezhaler ${ }^{\circledR}$ & 439 \\
\hline & & IND/MF high-dose $(150 / 320 \mu$ g o.d. $)$ via Breezhaler ${ }^{\circledR}$ & 445 \\
\hline & & MF medium-dose ( $400 \mu \mathrm{g}$ o.d.) via Twisthaler ${ }^{\circledR}$ & 444 \\
\hline & & MF high-dose $\left(800 \mu \mathrm{g}[400 \mu \mathrm{g}\right.$ b.i.d.] $)$ via Twisthaler $^{\circledR}$ & 442 \\
\hline & & SAL/FLU high-dose $\left(50 / 500 \mu\right.$ g b.i.d.) via Diskus ${ }^{\circledR}$ & 446 \\
\hline \multirow{5}{*}{$\begin{array}{l}\text { IRIDIUM } \\
\qquad(\text { NCT02571777) }\end{array}$} & \multirow[t]{5}{*}{52} & IND/GLY/MF medium-dose $(150 / 50 / 80 \mu$ g o.d. $)$ via Breezhaler ${ }^{\circledR}$ & 620 \\
\hline & & IND/GLY/MF high-dose $\left(150 / 50 / 160 \mu\right.$ g o.d.) via Breezhaler ${ }^{\circledR}$ & 619 \\
\hline & & IND/MF medium-dose $(150 / 160 \mu$ g o.d. $)$ via Breezhaler ${ }^{\circledR}$ & 617 \\
\hline & & IND/MF high-dose $\left(150 / 320 \mu\right.$ g o.d.) via Breezhaler ${ }^{\circledR}$ & 618 \\
\hline & & SAL/FLU high-dose $\left(50 / 500 \mu\right.$ g b.i.d.) via Diskus ${ }^{\circledR}$ & 618 \\
\hline \multirow{3}{*}{$\begin{array}{l}\text { ARGON } \\
\qquad(\text { NCT03158311) }\end{array}$} & \multirow[t]{3}{*}{24} & IND/GLY/MF medium-dose $(150 / 50 / 80 \mu$ g o.d. $)$ via Breezhaler ${ }^{\circledR}$ & 474 \\
\hline & & IND/GLY/MF high-dose $\left(150 / 50 / 160 \mu\right.$ g o.d.) via Breezhaler ${ }^{\circledR}$ & 476 \\
\hline & & $\begin{array}{l}\text { SAL/FLU high-dose }(50 / 500 \mu \text { b b.i.d. }) \text { via Diskus }{ }^{\circledR}+\text { TIO } 5 \mu \mathrm{g} \\
\text { o.d. via Respimat }{ }^{\circledR}\end{array}$ & 475 \\
\hline
\end{tabular}

b.i.d. twice daily, $F L U$ fluticasone propionate, $G L Y$ glycopyrronium bromide, $I N D$ indacaterol acetate, $M F$ mometasone furoate, $N$ number of patients randomized to study treatment, o.d. once daily, $S A L$ salmeterol xinafoate, $T I O$ tiotropium

studies were ongoing, accelerating the regulatory filing by ca. 7 months. This was made possible by the fact that although both studies were of 52 weeks' duration, both primary and key secondary endpoints were measured and analyzed at week 26 . This accelerated strategy supported regulatory submission by allowing for full analysis of the primary endpoint (trough $\mathrm{FEV}_{1}$ ), key secondary endpoints (ACQ-7), and other important secondary endpoints related to lung function and asthma control, including exacerbations while the study was ongoing, but after all patients completed at least 26 weeks of treatment. The studies continued until 52 weeks under the direction of a separate, fully blinded study team in order to maintain the integrity of the study data and subsequently analyze the remaining time points beyond 26 weeks, including long-term safety. This approach meant that, by the time of regulatory submission, the initial registration dossier contained more than $85 \%$ of the expected final data but after all patients completed at least 26 weeks of treatment. Approximately $64 \%$ of patients had completed the full 52-week treatment period, ca. $30 \%$ had variable exposure between 26 and 52 weeks, whereas the remaining ca. $6 \%$ had discontinued the treatment prematurely. Importantly, the submitted registration dossier contained fully adequate safety exposure per International Council for Harmonization of Technical Requirements for Pharmaceuticals for Human Use (ICH) guidelines. Additionally, the remainder of the data from the fully completed studies was submitted to Health Authorities at a later stage during the marketing authorization 
application review to enable them to consider the full study data in the decision process.

\section{Inclusion of an Additional Comparator in Phase III Studies: IRIDIUM and ARGON}

Another important feature in the development strategy of IND/GLY/MF was the inclusion of two different LABA/ICS comparators. In the pivotal phase III IRIDIUM study, IND/MF was selected as an internal comparator against IND/ GLY/MF to demonstrate the additional benefit of GLY [36], in line with CHMP combination guidance (EMA/CHMP/158268/2017). In addition, SAL/FLU was used as a marketed comparator, since it enabled demonstration of the effects of IND/GLY/MF and IND/MF together against SAL/FLU, a widely used treatment of asthma [36].

Similarly, the ARGON study was designed to compare the effect of o.d. IND/GLY/MF FDC versus concurrent administration of b.i.d. highdose SAL/FLU (via Diskus ${ }^{\circledR}$ ) and o.d. tiotropium (TIO [via Respimat ${ }^{\circledR}$ ]) [35].

Figure 2 shows the timeline plot depicting the single-development plan for IND/GLY/MF and IND/MF that accelerated approval of IND/ GLY/MF by ca. 4 years. Table 3 summarizes the unique approach adopted for clinical development to approval of the two FDCs.

\section{CLINICAL OVERVIEW}

The efficacy and safety of IND/GLY/MF was evaluated in the IRIDIUM and ARGON studies under the phase III PLATINUM program.

\section{IND/GLY/MF: Data from IRIDIUM and ARGON Studies}

The IRIDIUM study established the benefits of IND/GLY/MF versus internal comparator IND/ $\mathrm{MF}$ and the widely used standard-of-care SAL/ FLU, whereas the ARGON study demonstrated the effects of o.d. single-inhaler (Breezhaler ${ }^{\circledR}$ ) IND/GLY/MF versus concurrent administration of two approved treatments: b.i.d. high-dose SAL/FLU via Diskus ${ }^{\circledR}$ and o.d. TIO via Respimat ${ }^{\circledR}$ in patients with inadequately controlled asthma $[35,36]$.

\section{IRIDIUM (NCT02571777)}

The primary endpoint results showed that IND/GLY/MF medium-dose and high-dose (delivered via the Breezhaler ${ }^{\circledR}$ device) demonstrated superiority in improving trough forced expiratory volume in $1 \mathrm{~s}\left(\mathrm{FEV}_{1}\right)$ over IND/MF medium-dose $\quad(\Delta 76 \mathrm{~mL} \quad[95 \% \quad$ confidence interval (CI) 41-111]; $p<0.001$ ) and high-dose ( $\Delta 65 \mathrm{~mL}$ [95\% CI 31-99]; $p<0.001)$, respectively (both doses delivered via the Breezhaler ${ }^{\circledR}$ device) at week 26 (Fig. 3a) [36]. IND/GLY/MF medium-dose $(\Delta 99 \mathrm{~mL} \quad$ [95\% CI 64-133]; $p<0.001)$ and high-dose $(\Delta 119 \mathrm{~mL}[95 \% \mathrm{CI}$ $85-154]$; $p<0.001)$ showed greater improvements in trough $\mathrm{FEV}_{1}$ at week 26 compared with SAL/FLU high-dose (delivered via Diskus ${ }^{\circledR}$; Fig. 3a) [36]. Improvements were sustained at week 52. Furthermore, IND/GLY/MF showed greater improvement in evening and morning peak expiratory flow (PEF) than IND/MF and SAL/FLU over 52 weeks. The key secondary endpoint was improvement in Asthma Control Questionnaire (ACQ-7) score for IND/GLY/MF versus IND/MF at week 26. Although both treatments delivered clinically meaningful improvements from baseline in this measure, the key secondary endpoint was not met. However, differential improvements were observed with both doses of IND/GLY/MF versus SAL/FLU high-dose at week 26 [36]. The annualized rate of moderate or severe exacerbations, severe exacerbations, and all exacerbations decreased with IND/GLY/MF mediumand high-dose versus the corresponding dose of IND/MF [36]. Substantial reductions (36-42\%) in moderate-to-severe and severe asthma exacerbation rates were observed with IND/GLY/MF high-dose compared with SAL/ FLU high-dose, and even numerical reductions were observed with IND/GLY/MF medium-dose compared with SAL/FLU high-dose (Fig. 4a,b) [36]. The reduction in rescue medication use and daily asthma symptom scores and improvement in asthma quality-of-life questionnaire (AQLQ) scores were comparable between the IND/GLY/MF versus IND/MF or SAL/FLU groups [36]. Safety findings were 


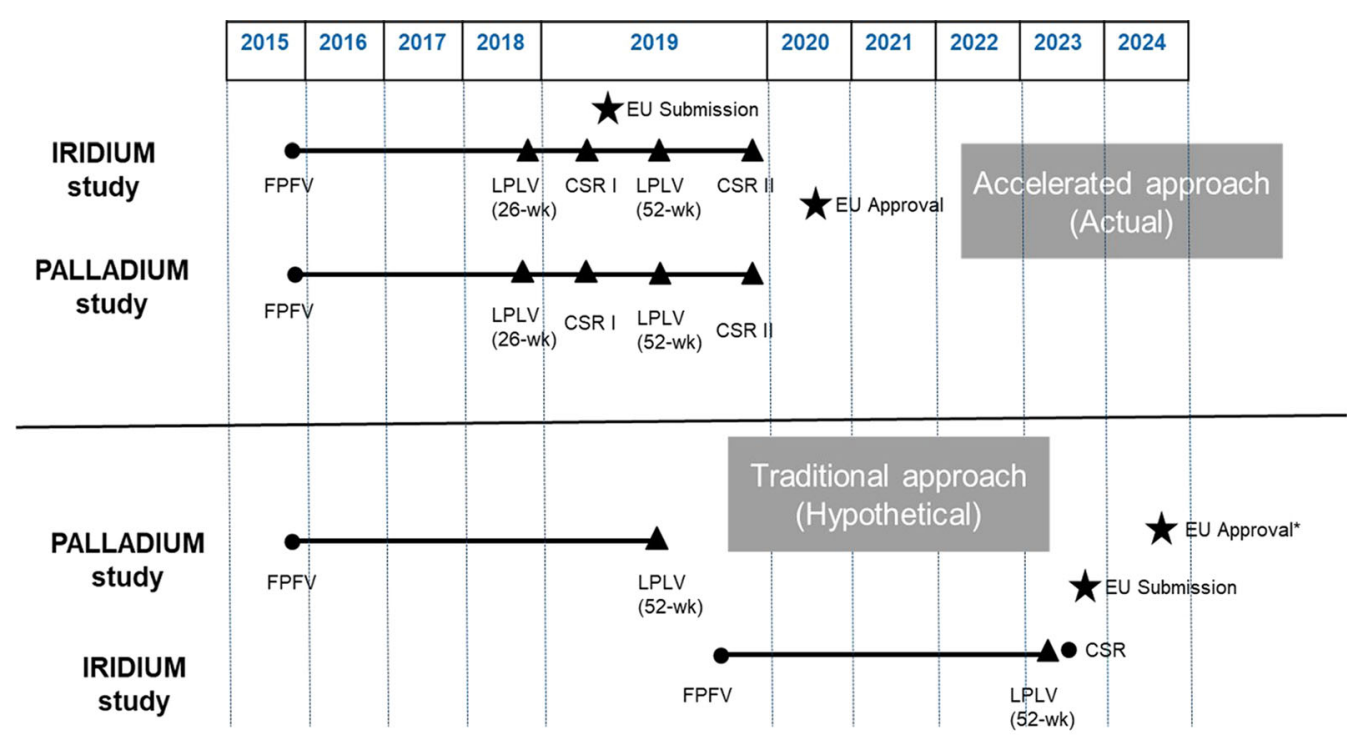

Fig. 2 Timeline plot depicting the single-development plan for IND/GLY/MF and IND/MF that accelerated approval of IND/GLY/MF by ca. 4 years. ${ }^{*} \mathrm{EU}$ approval for IND/GLY/MF. CSR I, clinical study report based on analysis after all patients completed at least 26 weeks of treatment (for primary/key secondary endpoints); CSR II,

clinical study report based on analysis after all patients completed 52 weeks (final CSR); EU, European Union; FPFV, first patient first visit; GLY, glycopyrronium bromide; IND, indacaterol acetate; LPLV, last patient last visit; MF, mometasone furoate

Table 3 Unique approach adopted from clinical development to approval of IND/GLY/MF and IND/MF

\begin{tabular}{|c|c|c|}
\hline & $\begin{array}{l}\text { Unique clinical development strategy for IND/GLY/ } \\
\text { MF }\end{array}$ & $\begin{array}{l}\text { Typical clinical development strategy for } \\
\text { combination therapies }\end{array}$ \\
\hline $\begin{array}{l}\text { Development } \\
\text { sequence }\end{array}$ & $\begin{array}{l}\text { Parallel development: IND/GLY/MF and IND/MF in } \\
\text { parallel; this accelerated development of IND/GLY/ } \\
\text { MF by ca. } 4 \text { years }\end{array}$ & $\begin{array}{l}\text { Stepwise: e.g., first dual combination then } \\
\text { triple combination }\end{array}$ \\
\hline $\begin{array}{l}\text { Phase III } \\
\text { comparator }\end{array}$ & $\begin{array}{l}\text { Two comparators: IND/MF as internal comparator; } \\
\text { SAL/FLU as marketed comparator }\end{array}$ & $\begin{array}{l}\text { One comparator: internal comparator (dual } \\
\text { combination) }\end{array}$ \\
\hline $\begin{array}{l}\text { Submission to } \\
\text { regulatory } \\
\text { authorities }\end{array}$ & $\begin{array}{l}\text { Submission while studies were ongoing (accelerated } \\
\text { approval process by ca. } 7 \text { months), with long-term } \\
\text { safety provided through variable exposure periods }\end{array}$ & $\begin{array}{l}\text { Submission only upon completion of clinical } \\
\text { trial program }\end{array}$ \\
\hline $\begin{array}{l}\text { Digital } \\
\text { companion }\end{array}$ & $\begin{array}{l}\text { Incorporation in initial Marketing Authorization } \\
\text { Application }\end{array}$ & $\begin{array}{l}\text { Not part of Marketing Authorization } \\
\text { Application (either not submitted at all, or } \\
\text { submitted after approval) }\end{array}$ \\
\hline
\end{tabular}

$I N D$ indacaterol acetate, $F L U$ fluticasone propionate, GLY glycopyrronium bromide, $M F$ mometasone furoate, $S A L$ salmeterol xinafoate

consistent with the known safety profiles of LABA, LAMA, and ICS drug classes in asthma $[36,39]$.
ARGON (NCTO3158311)

Once-daily IND/GLY/MF medium-dose $(\Delta-0.038 ; p<0.001)$ and high-dose $(\Delta 0.073$; 


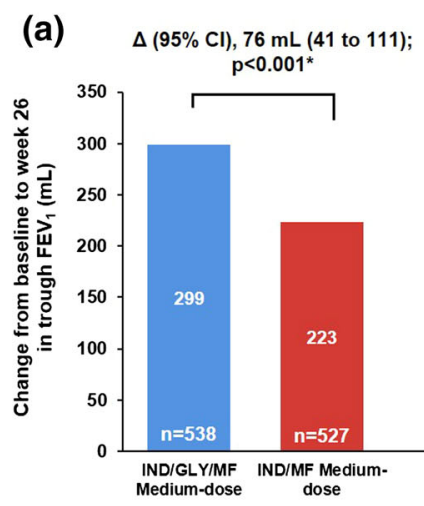

$\Delta(95 \% \mathrm{Cl}), 76 \mathrm{~mL}$ (41 to 111$)$;

(a) $\begin{aligned} & \mathrm{p}<0.001^{*} \\ &\end{aligned}$

(b)

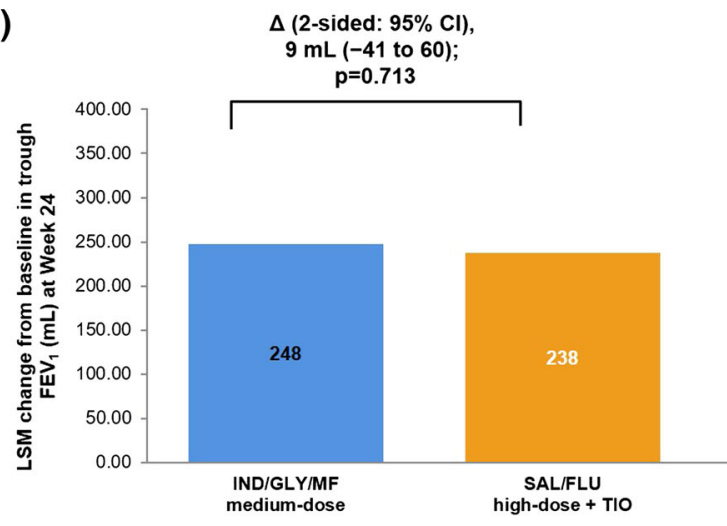

Fig. 3 Change from baseline in trough $\mathrm{FEV}_{1}$ : a IND/ GLY/MF versus IND/MF and SAL/FLU at week 26 (IRIDIUM), b IND/GLY/MF versus SAL/FLU + TIO at week 24 (ARGON). Data are presented as LSM. ${ }^{*} p \leq 0.05$. IND/GLY/MF medium-dose, IND/GLY/MF 150/50/80 $\mu$ g o.d.; IND/GLY/MF high-dose, IND/GLY/ MF 150/50/160 $\mu$ g o.d.; IND/MF medium-dose, IND/ MF 150/160 $\mu$ g o.d.; IND/MF high-dose, IND/MF $150 / 320 \mu$ o.d.; SAL/FLU high-dose, SAL/FLU $50 / 500 \mu \mathrm{g}$ b.i.d.; TIO, TIO $5 \mu \mathrm{g}$ o.d. $\Delta=$ treatment difference; b.i.d., twice daily; $\mathrm{CI}$, confidence interval; $\mathrm{FEV}_{1}$, forced expiratory volume in $1 \mathrm{~s}$; FLU, fluticasone propionate; GLY, glycopyrronium bromide; IND, indacaterol acetate; LSM, least squares mean; MF, mometasone furoate; o.d., once daily; SAL, salmeterol xinafoate; TIO,

$p<0.001$; both doses delivered via the Breezhaler ${ }^{\circledR}$ device) met the primary endpoint, demonstrating non-inferiority to concurrent administration of two existing inhaled medications: b.i.d. SAL/FLU high-dose (delivered via Diskus ${ }^{\circledR}$ ) plus o.d. TIO (delivered via Respimat $^{\circledR}$ ) in improving AQLQ score at week 24 [35]. Greater improvements in trough $\mathrm{FEV}_{1}$, forced vital capacity, ACQ-7 scores, tiotropium. a "Reprinted from Lancet Respir Med. Kerstjens HAM et al., Once-daily, single-inhaler mometasone-indacaterol-glycopyrronium versus mometasone-indacaterol or twice-daily fluticasone-salmeterol in patients with inadequately controlled asthma (IRIDIUM): a randomised, double-blind, controlled phase 3 study, vol 8, pp 1000-1012. Copyright 2020, with permission from Elsevier." b "Reprinted from Respir Med. Gessner C et al., Fixed-dose combination of indacaterol/glycopyrronium/mometasone furoate once-daily versus salmeterol/ fluticasone twice-daily plus tiotropium once-daily in patients with uncontrolled asthma: a randomised, phase IIIb, non-inferiority study (ARGON), vol 170, pp 106021. Copyright 2020, with permission from Elsevier"

evening and morning PEF and St. George's Respiratory Questionnaire (SGRQ) score were observed at week 24 with IND/GLY/MF highdose compared with SAL/FLU high-dose plus TIO, while comparable benefits were seen with IND/GLY/MF medium-dose versus SAL/FLU high-dose plus TIO but with a lower ICS dose treatment (Fig. 3b) [35]. The rate of all exacerbations and moderate or severe exacerbations 

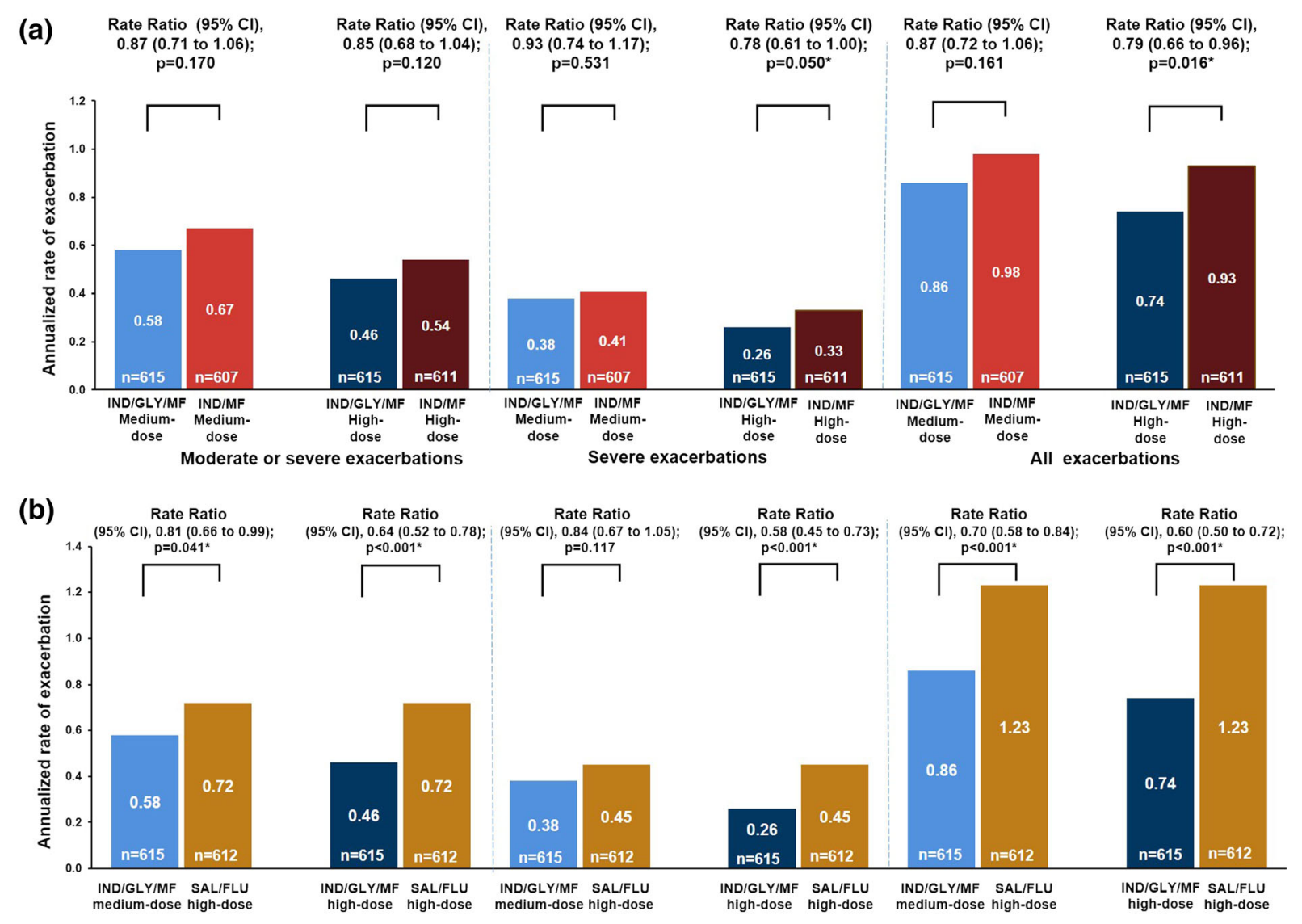

Moderate or severe exacerbations

Severe exacerbations

All exacerbations

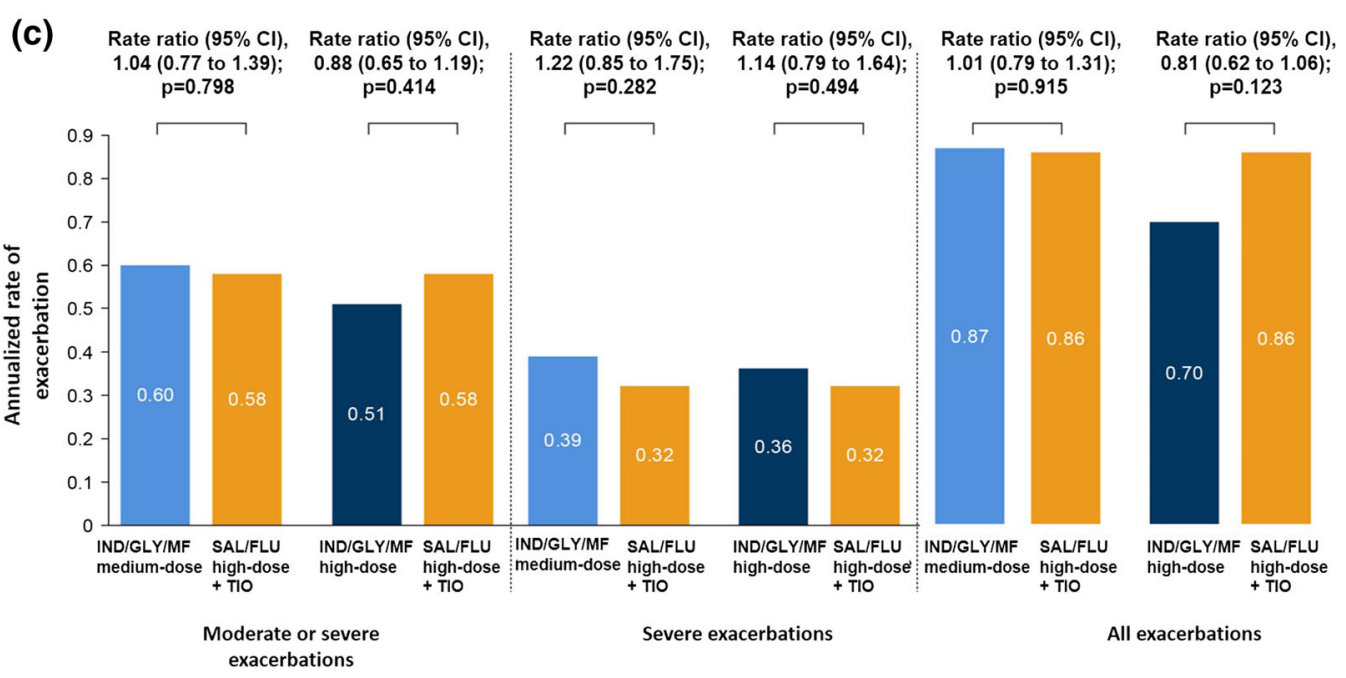


4Fig. 4 Annualized rate of exacerbations with: a IND/ GLY/MF versus IND/MF over 52 weeks (IRIDIUM), b IND/GLY/MF versus SAL/FLU over 52 weeks (IRIDIUM), c IND/GLY/MF versus SAL/FLU + TIO over 24 weeks (ARGON). Data are presented as annualized rates. ${ }^{*} p \leq 0.05$. IND/GLY/MF medium-dose, IND/ GLY/MF 150/50/80 $\mu$ g o.d.; IND/GLY/MF high-dose, IND/GLY/MF 150/50/160 $\mu$ g o.d.; IND/MF mediumdose, IND/MF 150/160 $\mu$ g o.d.; IND/MF high-dose, IND/MF 150/320 $\mu \mathrm{g}$ o.d.; SAL/FLU high-dose, SAL/ FLU 50/500 $\mu$ g b.i.d.; TIO, TIO $5 \mu \mathrm{g}$ o.d. b.i.d., twice daily; CI, confidence interval; FLU, fluticasone propionate; GLY, glycopyrronium bromide; IND, indacaterol acetate; MF, mometasone furoate; o.d., once daily; SAL, salmeterol xinafoate; TIO, tiotropium. a, b "Reprinted from Lancet Respir Med. Kerstjens HAM et al., Once-daily, singleinhaler mometasone-indacaterol-glycopyrronium versus mometasone-indacaterol or twice-daily fluticasone-salmeterol in patients with inadequately controlled asthma (IRIDIUM): a randomised, double-blind, controlled phase 3 study, vol 8, pp 1000-1012. Copyright 2020, with permission from Elsevier." c "Reprinted from Respir Med. Gessner C et al., Fixed-dose combination of indacaterol/ glycopyrronium/mometasone furoate once-daily versus salmeterol/fluticasone twice-daily plus tiotropium oncedaily in patients with uncontrolled asthma: A randomised, phase IIIb, non-inferiority study (ARGON), vol 170, pp 106021. Copyright 2020, with permission from Elsevier"

was comparable between either doses of IND/ GLY/MF versus SAL/FLU high-dose plus TIO (Fig. 4c) [35]. The safety profile with IND/GLY/ MF was comparable to that of SAL/FLU highdose plus TIO [35, 39].

\section{SUMMARY}

The limited availability of treatment options in the severe asthma population underscores the need for innovative development strategies to bring new medications to patients. Taken together with lengthy timelines for a traditional "sequential" development program, these challenges led us to utilize a novel strategy that accelerated the development of o.d. IND/GLY/
MF by ca. 4 years, thereby enabling earlier patient access to this treatment. Despite being an accelerated development plan, this strategy maintained a robust pivotal study design to allow for thorough assessment of efficacy as well as safety. As a result, o.d. IND/GLY/MF delivered via Breezhaler ${ }^{\circledR}$ became the first LABA/LAMA/ ICS FDC to be approved as a maintenance treatment in patients with asthma inadequately controlled with LABA/ICS [3, 40]. Moreover, for the first time, an optional digital companion, comprising an electronic sensor and app that provide inhalation confirmation, medication reminders, and access to objective data to better support therapeutic decisions is also covered under approval by the European Commission [3]. In parallel, IND/MF, an o.d. LABA/ICS delivered via the Breezhaler ${ }^{\circledR}$, was also approved for treatment of asthma inadequately controlled with ICS and short-acting beta agonists [41, 42].

Data from the IRIDIUM and ARGON studies emphasized the potential benefits of IND/GLY/ MF for patients with inadequately controlled asthma. In the IRIDIUM study, IND/GLY/MF showed beneficial effects compared with both IND/MF and SAL/FLU [36]. IND/MF, developed in parallel with IND/GLY/MF, showed favorable benefits compared with MF alone and compared with widely used high-dose SAL/ FLU, with longer and sustained bronchodilation $[37,38]$. In the ARGON study, the efficacy of IND/GLY/MF delivered through a single inhaler was compared with concurrent administration of two existing inhaled medicines: SAL/FLU and TIO, delivered through different inhalers [35].

w? >In conclusion, the potential to translate the clinical benefits seen with o.d. single-inhaler IND/GLY/MF and IND/MF asthma therapies into the real world has been accelerated by ca. 4 years-thanks to a unique development strategy. Together with the Breezhaler ${ }^{\circledR}$ device and an optional digital companion, designed to simplify the use and optimize medication adherence by patients, it is hoped that these 
medicines can help contribute toward meeting some of the unmet needs in asthma healthcare.

\section{ACKNOWLEDGEMENTS}

Funding. Rapid Service and Open Access Fee was funded by Novartis Pharma AG, Basel, Switzerland.

Medical Writing, Editorial, and Other Assistance. The authors thank Phani Dantu, Asma S and Rahul Lad (Novartis Healthcare Pvt. Ltd. India) for providing medical writing support/editorial support, which was funded by Novartis, in accordance with Good Publication Practice (GPP3) guidelines (http://www.ismpp. org/gpp3).

Authorship. All named authors meet the International Committee of Medical Journal Editors (ICMJE) criteria for authorship for this article, take responsibility for the integrity of the work as a whole, and have given their approval for this version to be published.

Author Contributions. All authors were involved in drafting, writing, and reviewing the manuscript, and all authors read and approved the final manuscript.

Disclosures. Dominic Brittain, Peter D’Andrea, Emilie Gruen, Motoi Hosoe, Devendra Jain, Juergen Jauernig, Abhijit Pethe, Emil Scosyrev, Ana-Maria Tanase and Hanns-Christian Tillman are employees of Novartis.

Compliance with Ethics Guidelines. This article is based on previously conducted studies and does not contain any new studies with human participants or animals performed by any of the authors.

Open Access. This article is licensed under a Creative Commons Attribution-NonCommercial 4.0 International License, which permits any non-commercial use, sharing, adaptation, distribution and reproduction in any medium or format, as long as you give appropriate credit to the original author(s) and the source, provide a link to the Creative Commons licence, and indicate if changes were made. The images or other third party material in this article are included in the article's Creative Commons licence, unless indicated otherwise in a credit line to the material. If material is not included in the article's Creative Commons licence and your intended use is not permitted by statutory regulation or exceeds the permitted use, you will need to obtain permission directly from the copyright holder. To view a copy of this licence, visit http://creativecommons.org/licenses/by$\mathrm{nc} / 4.0 /$.

\section{REFERENCES}

1. Enerzair $^{\circledR}$ Breezhaler $^{\circledR}$. Summary of product characteristics (SmPC). Last updated 12 May 2021. https://www.medicines.org.uk/emc/product/ 11886/smpc\#gref. Accessed 26 Sept 2021.

2. Atectura ${ }^{\circledR}$ Breezhaler ${ }^{\circledR}$. Summary of product characteristics (SmPC). Last updated 11 Aug 2021. https://www.medicines.org.uk/emc/product/ 11885/smpc. Accessed 26 Sept 2021.

3. Novartis receives EC approval for Enerzair ${ }^{\circledR}$ Breezhaler $^{\circledR}$, including the first digital companion (sensor and app) that can be prescribed alongside a treatment for uncontrolled asthma in the EU. Media Release. https://www.novartis.com/news/ media-releases/novartis-receives-ec-approvalenerzair-breezhaler-including-first-digitalcompanion-sensor-and-app-can-be-prescribedalongside-treatment-uncontrolled-asthma-eu. Accessed 26 Sept 2021.

4. EMA's transformative treatments of 2020. https:// www.europeanpharmaceuticalreview.com/article/ 143977/emas-transformative-treatments-of-2020/. Accessed 26 Sept 2021.

5. Katsaounou P, Odemyr M, Spranger O, et al. Still fighting for breath: a patient survey of the challenges and impact of severe asthma. ERJ Open Res. 2018;4:00076-2018.

6. Peters SP, Ferguson G, Deniz Y, Reisner C. Uncontrolled asthma: a review of the prevalence, disease burden and options for treatment. Respir Med. 2006;100:1139-51.

7. Price D, Fletcher M, van der Molen T. Asthma control and management in 8,000 European 
patients: the REcognise Asthma and LInk to Symptoms and Experience (REALISE) survey. NPJ Prim Care Respir Med. 2014;24:14009.

8. Global Initiative for Asthma. Global strategy for asthma management and prevention. 2021. http:// www.ginasthma.org. Accessed 26 Sept 2021.

9. Makela MJ, Backer V, Hedegaard M, Larsson K. Adherence to inhaled therapies, health outcomes and costs in patients with asthma and COPD. Respir Med. 2013;107:1481-90.

10. Murphy KR, Bender BG. Treatment of moderate to severe asthma: patient perspectives on combination inhaler therapy and implications for adherence. J Asthma Allergy. 2009;2:63-72.

11. Engelkes M, Janssens HM, de Jongste JC, Sturkenboom MC, Verhamme KM. Medication adherence and the risk of severe asthma exacerbations: a systematic review. Eur Respir J. 2015;45:396-407.

12. Greene G, Costello RW. Personalizing medicinecould the smart inhaler revolutionize treatment for COPD and asthma patients? Expert Opin Drug Deliv. 2019;16:675-7.

13. Johnson N, Varughese B, De La Torre MA, Surani SR, Udeani G. A review of respiratory biologic agents in severe asthma. Cureus. 2019;11:e5690.

14. Barnes PJ, Bonini S, Seeger W, Belvisi MG, Ward B, Holmes A. Barriers to new drug development in respiratory disease. Eur Respir J. 2015;45:1197-207.

15. Onbrez Breezhaler 150 microgram inhalation powder, hard capsules. Summary of product characteristics (SmPC). Last updated 08 Jan 2021. https:// www.medicines.org.uk/emc/product/7794/smpc. Accessed 26 Sept 2021.

16. Zafar MA, Droege C, Foertsch M, Panos RJ. Update on ultra-long-acting beta agonists in chronic obstructive pulmonary disease. Expert Opin Investig Drugs. 2014;23(12):1687-701.

17. Seebri Breezhaler 44 micrograms inhalation powder, hard capsules. Summary of product characteristics (SmPC). Last updated 09 Jan 2020. https:// www.medicines.org.uk/emc/product/2840. Accessed 26 Sept 2021.

18. Ultibro Breezhaler 85 micrograms/43 micrograms inhalation powder hard capsules. Summary of product characteristics. Last updated 04 Dec 2020. https://www.medicines.org.uk/emc/product/3496. Accessed 26 Sept 2021.

19. Hansel TT, Neighbour H, Erin EM, et al. Glycopyrrolate causes prolonged bronchoprotection and bronchodilatation in patients with asthma. Chest. 2005;128(4):1974-9.

20. Pearlman DS, Greos L, LaForce C, Orevillo CJ, Owen $\mathrm{R}$, Higgins $\mathrm{M}$. Bronchodilator efficacy of indacaterol, a novel once-daily beta2-agonist, in patients with persistent asthma. Ann Allergy Asthma Immunol. 2008;101(1):90-5.

21. McCormack PL, Plosker GL. Inhaled mometasone furoate: a review of its use in persistent asthma in adults and adolescents. Drugs. 2006;66(8):1151-68.

22. Tan RA, Corren J. Mometasone furoate in the management of asthma: a review. Ther Clin Risk Manag. 2008;4(6):1201-8.

23. Asmanex Twisthaler 400 micrograms Inhalation Powder. Summary of product characteristics. Last updated 17 Feb 2021. https://www.medicines.org. uk/emc/product/6753/smpc. Accessed 26 Sept 2021.

24. Clinicaltrials.gov. Efficacy, safety and pharmacokinetics of indacaterol acetate in patients with persistent asthma (CQMF149E2203). Last updated 27 Jan 2015. https://www.clinicaltrials.gov/ct2/show/ results/NCT01609478?term=

CQMF149E2203\&draw $=2 \&$ rank $=1$. Accessed 26 Sept 2021.

25. Miller D, Vaidya S, Jauernig J, et al. Lung function, pharmacokinetics, and tolerability of inhaled indacaterol maleate and acetate in asthma patients. Respir Res. 2020;21(1):248.

26. Seebri Breezhaler. Summary of product characteristics (SmPC). Last updated 09 Jan 2020. https:// www.medicines.org.uk/emc/product/2840. Accessed 26 Sept 2021.

27. Vaidya S, Ziegler D, Tanase AM, et al. Pharmacokinetics of mometasone furoate delivered via two dry powder inhalers. Pulm Pharmacol Ther. 2021;70: 102019.

28. Buhl R, Nikolaev I, Tillmann HC, et al. Dose bridging data for mometasone furoate in once-daily fixed-dose inhaled combinations of mometasone furoate/indacaterol and mometasone furoate/indacaterol/glycopyrronium in patients with asthma. Pulm Pharmacol Ther. 2021;70:102068.

29. Buhl R, Tanase AM, Hosoe M, et al. A randomized, double-blind study to compare the efficacy and safety of two doses of mometasone furoate delivered via Breezhaler ${ }^{\circledR}$ or Twisthaler ${ }^{\circledR}$ in patients with asthma. Pulm Pharmacol Ther. 2020;62:101919.

30. Vaidya SS, Khindri S, Calder N, et al. Pharmacokinetics of indacaterol and mometasone furoate delivered alone or in a free or fixed dose 
combination in healthy subjects. Pulm Pharmacol Ther. 2016;37:30-6.

31. Dal Negro RW. Dry powder inhalers and the right things to remember: a concept review. Multidiscip Respir Med. 2015;10(1):13.

32. Panigone S, Sandri F, Ferri R, Volpato A, Nudo E, Nicolini G. Environmental impact of inhalers for respiratory diseases: decreasing the carbon footprint while preserving patient-tailored treatment. BMJ Open Respir Res. 2020;7(1):e000571.

33. Aumônier S, Whiting A, Norris S, Collins M, Coleman T, Fulford B, Breitmayer E. Carbon footprint assessment of Breezhaler ${ }^{\circledR}$ dry powder inhaler. Drug Delivery to the Lungs. Vol. 31. 2020. https:// ddl-conference.com/ddl2020-christmas-lectures/ conference-papers/carbon-footprint-assessmentofbreezhaler-dry-powder-inhaler/

34. Hillman T, Mortimer F, Hopkinson NS. Inhaled drugs and global warming: time to shift to dry powder inhalers. BMJ. 2013;346:f3359.

35. Gessner C, Kornmann O, Maspero J, et al. Fixeddose combination of indacaterol/glycopyrronium/mometasone furoate once-daily versus salmeterol/fluticasone twice-daily plus tiotropium once-daily in patients with uncontrolled asthma: a randomised, phase IIIb, non-inferiority study (ARGON). Respir Med. 2020;170:106021.

36. Kerstjens HAM, Maspero J, Chapman KR, et al. Once-daily, single-inhaler mometasone-indacaterol-glycopyrronium versus mometasone-indacaterol or twice-daily fluticasone-salmeterol in patients with inadequately controlled asthma (IRIDIUM): a randomised, double-blind, controlled phase 3 study. Lancet Respir Med. 2020;8(10): 1000-12.

37. Kornmann O, Mucsi J, Kolosa N, et al. Efficacy and safety of inhaled once-daily low-dose indacaterol acetate/mometasone furoate in patients with inadequately controlled asthma: phase III randomised QUARTZ study findings. Respir Med. 2020;161: 105809.

38. van Zyl-Smit RN, Krüll M, Gessner C, et al. Oncedaily mometasone plus indacaterol versus mometasone or twice-daily fluticasone plus salmeterol in patients with inadequately controlled asthma (PALLADIUM): a randomised, double-blind, triple-dummy, controlled phase 3 study. Lancet Respir Med. 2020;8(10):987-99.

39. Scosyrev E, van Zyl-Smit R, Kerstjens H, et al. Cardiovascular safety of mometasone/indacaterol and mometasone/indacaterol/glycopyrronium oncedaily fixed-dose combinations in asthma: pooled analysis of phase 3 trials. Respir Med. 2021;180: 106311 .

40. European Commission. Union Register of medicinal products for human use-Enerzair Breezhaler. Last updated 27 July 2021. https:/ec.europa.eu/ health/documents/community-register/html/ h1438.htm. Last accessed 24 Sept 2021.

41. Novartis receives simultaneous approval for five new products from Japanese Ministry of Health, Labour and Welfare, offering Japanese patients a broad range of novel treatment options. Press release. https://www.globenewswire.com/en/newsrelease/2020/06/29/2054449/0/en/Novartis-receivessimultaneous-approval-for-five-new-products-fromJapanese-Ministry-of-Health-Labour-and-Welfareoffering-Japanese-patients-a-broad-range-of-noveltreatment-option.html. Last accessed 24 July 2021.

42. European Commission. Union Register of medicinal products for human use-Atectura Breezhaler. Last updated 26 Apr 2021. https://ec.europa.eu/ health/documents/community-register/html/ h1439.htm. Last accessed 24 July 2021. 